\title{
Should the "CLOUD" be Regulated? An Assessment
}

\section{Abbas Strømmen-Bakhtiar Centre for Enterprise Architecture and Information Systems Bodø Graduate School of Business, University of Nordland, Norway}

\author{
abbas.strommen.bakhtiar@gmail.com
}

\author{
Amir R. Razavi \\ University of Surrey, UK \\ a.razavi@surrey.ac.uk
}

\begin{abstract}
We are currently going through a transitional period, moving from the service era to the information era, where the major part of the society, is or soon will be, engaged in creating, distributing, using, integrating or manipulating information in one form or the other. In the information era, access to information is as critical to the welfare of the society as electricity is today. And as with electricity where people and businesses moved from make your own to the utility model; they are now moving from having their own computers and datacentres to the utility model of the cloud computing.

Cloud computing promises to be the ultimate outsourcing solution to all: from the individual users to small businesses, as well as large enterprises and even governments. Many large corporations are already investing heavily in cloud computing hoping to take advantage of being the first mover (technological leadership, pre-emption of assets, and buyer switching costs).

This article discusses the issue of cloud or utility computing as the $5^{\text {th }}$ utility; arguing that cloud computing (primarily public clouds) should be regulated just like other utilities, lest we face the same problems that we faced in the birth of other utilities (gas, electric, water, telephone, etc).

Keywords: Cloud Computing, Utility Computing, Information Era, Knowledge-based Economy, Economies of Scale, Natural Monopoly, Primary Sector, Secondary Sector, Tertiary Sector, Quaternary Sector.
\end{abstract}

\section{Introduction}

The evolution of IT infrastructure and services has been described as one that has moved from mainframes, to PCs to Client Server to Enterprise Internet; and finally it is moving towards the

Material published as part of this publication, either on-line or in print, is copyrighted by the Informing Science Institute. Permission to make digital or paper copy of part or all of these works for personal or classroom use is granted without fee provided that the copies are not made or distributed for profit or commercial advantage AND that copies 1) bear this notice in full and 2) give the full citation on the first page. It is permissible to abstract these works so long as credit is given. To copy in all other cases or to republish or to post on a server or to redistribute to lists requires specific permission and payment of a fee. Contact Publisher@InformingScience.org to request redistribution permission. ultimate outsourcing solution: the cloud computing (Laudon \& Laudon, 2009).

"Cloud computing" is the term given to computing based on sharing computing hardware and software resources; and as such it is based on years of research in virtualization, distributed computing, and more recently networking, web and software services (Vouk, 2004). Cloud computing is about to usher in the era of 
on-demand computing products and services to all who have access to the Internet.

Rosenberg and Mateos (2010) argue that with very few notable exceptions there are five main principles behind cloud computing. These principles are:

- Pooled computing resources available to any subscribing user (availability);

- Virtualized computing resources to maximize hardware utilization (high utilization);

- Elastic scaling up or down according to need (dynamic scale without Capital Expenditure or CAPEX);

- Automated creation of new virtual machines or deletion of existing ones (build, deploy, configure, provide, and move, all without manual intervention);

- Resource usage billed as used (per-usage business model).

The first principle, pooled computing, refers to any internal or external pooled non-dedicated computing assets available to any subscribing user. The second principle, the virtualization of computing resources, allows the high utilization of pooled resources. This is especially important when one considers the cost and the number of servers involved. High utilization is vital in managing costs.

The third principle offers elasticity or dynamic scalability - meaning that resources become available as needed, a kind of just-in-time system where resources are provided according to the need of the customer/user. This in turn requires a dynamic creation/deletion of virtual machines (the fourth principle). As the need for resources rise, the instances of virtual machines/applications are made available and as the needs ebb, those instances are deleted; which brings us to the fifth and the final principle: the billing. Since the resources are made available and used according to the customers' needs, the billing has to reflect the resources consumed; hence the metering model.

One of the main attractions of cloud computing for businesses is of course the attraction of marked reduction in expenditure on infrastructure (conversion of capital expenditure or CAPEX to operational expenditure or OPEX). However, outsourcing of IT infrastructure is only one layer, upon which other layers reside; each of which present other cost saving advantages, not to mention the flexibility and agility that they provide. Here we can list the layers (Weinhardt et al., 2011) as the user applications (Software as a Service or SaaS), the developer (Platform as a Service or PaaS), and of course the above mentioned IT infrastructure (Infrastructure as a Service or IaaS). The cloud encompasses all these layers, making it one of the ultimate outsourcing systems for all of the users' computing infrastructure and services.

As can be expected, the cloud computing is an exceptionally attractive proposition for all types of users, especially businesses, large organizations and even local and national governments, not to mention the ordinary users (who incidentally are already using the cloud, for example, for emails, sharing photos and documents). The promise of access to 'seemingly' unlimited resources is simply too attractive to ignore. Indeed, this promise is so alluring that some already are calling the cloud computing the 5th utility (Buyya et al., 2009) (after water, gas, electricity, and telephony).

\section{Economies of Scale and Natural Monopoly}

Cloud computing is changing the way businesses compete in the marketplace. We see, for example, that Cloud Computing to a large extent can level the business playing field (in a digital business ecosystem), bringing with it the advantages of economies of scale and economies of scope to all actors on the three levels (SaaS, PaaS, and IaaS). This is especially important for Small and 
Medium-size Enterprises (SMEs) since it allows innovative small firms to grow rapidly and compete in par with the large corporations.

"According to new research, more than half of small and medium sized companies plan to use cloud computing in 2010. In response to this trend, practice accountants are increasingly looking to cloud computing as a means of managing financial data, improving remote access to client data and reducing overhead costs. However, there are still many real concerns relating to loss of data control that has been holding many organisations back." (Griffin, et al., 2010)

There is double digit growth in the cloud market. According to various market estimates by IBM, "The global cloud computing market is expected to grow at a compounded annual rate of 28 percent from $\$ 47$ billion in 2008 to $\$ 126$ billion by 2012" («Panasonic Ushers in the Cloud Computing Era with IBM LotusLive», 2010)

To facilitate this rapid expansion in demand, large corporations such as Google, Microsoft, Yahoo, Amazon, IBM and others are investing heavily in cloud infrastructure, building mega data centres around the world. According to Rosenberg and Mateos (2010), these facilities already account for $1.2 \%$ of the U.S.'s total electricity usage. With rapidly increasing demand and investment this figure is bound to rise even further.

It goes without saying that for societies that embrace cloud computing, access to the cloud will become as important as access to electricity. "Before the rise of the electric utility, businesses and individuals had to generate their own power to run their machines. However, when large electric producers began generating power and delivering it via transmission lines into factories, buildings, and homes, self-generation of power waned due to the cost-efficiency and convenience of having reliable electricity on-demand" (Wyld, 2009, p.4). We see that this change is happening with computing as well - going from owner generated and maintained computing to the cloud computing. And as with the case of electricity, this move from self generation to utility model will be exponential.

This massive move to the cloud and the promise of reduction of costs through the economies of scale raises the problem of the creation of monopolies. When it comes to ICT in general and cloud computing in particular, three main sources of monopolies stand out: resource scarcity, high entry barriers (Notebaert, 1995), and controlling the platform upon which the cloud computing is constructed. The first (i.e. resource scarcity) can, for example point to the scarcity of bandwidth to access the services on the cloud. Here we can mention the power of ISPs, carriers etc. The second source (the high entry barrier) can point to the economies of scale. Heavy investment in infrastructure by few actors can create such economies of scale that it effectively excludes any other would be competitor from the market. The third source of monopoly is controlling the platform. If one has the control over the platform (including standards), one can easily capture the upper layers by either buying the main actors at each layer or simply merging with them, to create a formidable force to dominate those layers and create a near monopoly situation.

A good example of this is provided by the Microsoft Corporation. which used the dominance of its operating system to capture the office package, browser and e-mail markets. Although Microsoft's near monopoly in these markets lasted for only a few decades, it still maintains its dominant position in PC operating system and office products. For example, as of 2007 Microsoft Office had close to $95 \%$ of the market share («Rivals Set Their Sights on Microsoft Office: Can They Topple the Giant? », 2007), this despite the availability of free OpenOffice products.

As was mentioned earlier, several large actors are investing heavily to create mega datacentres and associated services. One or a combination of several of these actors can (given the current trend) try to 'corner the market', creating monopolies or oligopolies; or at the very least erect 
huge entry barriers limiting the number of providers to only a few. This is especially worrisome when one considers the infrastructure element of the cloud. Infrastructure, because of the level of investment necessary, is where 'natural monopoly' can easily arise.

"The term does not refer to the actual number of sellers in a market but to the relationship between demand and the technology of supply. If the entire demand within a relevant market can be satisfied at lowest cost by one firm, either the firms will quickly shake down to one through mergers or failures, or production will continue to consume more resources than necessary. In the first case competition is short-lived and in the second it produces inefficient results. Competition is thus not a viable regulatory mechanism under conditions of natural monopoly. Hence, it is said, direct controls are necessary to ensure satisfactory performance: control over profits, specific rates, quality of service, extensions and abandonments of service and plant, even permission whether to enter the business at all. This set of controls has been applied mainly to gas, water, and electrical companies, where it is known as "public utility regulation" to providers of public transportation and telecommunications, where it is known as "common carrier regulation." (Berg \& Tschirhart, 1989)

The natural monopoly phenomenon is dependent on the premise that the entire demand within a relevant market can be satisfied at lowest cost by one firm. As we shall see this economies of scale is at the root of the cloud computing. According to Armburst et al. (2009) citing James Hamilton (2008), the cost advantages of economies of scale are huge. An example of this cost advantage can be seen in Table 1 .

Economies of scale in 2006 for medium-sized datacentre ( $\approx 1000$ servers $)$ vs. very large datacentre $(\approx 50,000$ servers $)$.

Table 2 presents the costs of computing resources for 2003 to 2008. It shows a clear and marked reduction in prises. This steady decline in prices can be attributed to two points: a real general reduction in hardware costs, and the economies of scales. The general reduction in hardware costs affect all in the same way and cannot bring competitive advantage to any actor. However, the economies of scale can. That is to say, large corporations can get large discounts on hardware when constructing large datacentres.

Table 1. Economies of Scale and cost advantage

\begin{tabular}{|l|c|c|c|}
\hline \multicolumn{1}{|c|}{ Technology } & Cost in Medium-sized DC & Cost in Very Larg DC & Ratio \\
\hline Nerwork & $\$ 95$ per Mbit/sec/month & $\$ 13$ per Mbit/sec/month & $7: 1$ \\
\hline Storage & $\$ 2.20$ per Gbyte/month & $\$ 0.40$ per Gbyte/month & $6: 1$ \\
\hline Administration & $\approx 140$ Servers/Administraor & $>1000$ Server/Administrator & $7: 1$ \\
\hline
\end{tabular}

Source: Armbrust, M., A. Fox, R. Griffith, A. D. Joseph, R. Katz, A. Konwinski. 'Above the Clouds: A Berkeley View of Cloud Computing', Technical Report No (UCB/EECS-2009-28, UC Berkeley Reliable Adaptive Distributed Systems Laboratory, February, 2009.) 
Table 2. The costs of computing resources from 2003 to 2008 , normalized to what $\$ 1$ could buy in 2003 vs. 2008 , and compared to the cost of paying per use of \$1 worth of resources on Amazon Web Services (AWS) at 2008 prices.

\begin{tabular}{|c|c|c|c|}
\hline & WAN bandwidth/month & CPU hours (all cores) & Disk Storage \\
\hline Items in 2003 & 1Mbps WAN link & 2GHz CPU, 2GB DRAM & $200 \mathrm{~GB}$ disk, $50 \mathrm{Mb} / \mathrm{s}$ transfe rate \\
\hline Cost in 2003 & $\$ 100 /$ month & $\$ 2000$ & $\$ 200$ \\
\hline$\$ 1$ buys in 2003 & $1 \mathrm{~GB}$ & $8 \mathrm{CPU}$ hours & $1 \mathrm{~GB}$ \\
\hline Item in 2008 & $100 \mathrm{Mbps}$ WAN link & $\begin{array}{l}2 \mathrm{GHz}, 2 \text { sockets, } 4 \\
\text { cores/socket, } 4 \text { GB DRAM }\end{array}$ & $\begin{array}{l}1 \mathrm{~TB} \text { disk, } 115 \mathrm{MB} / \mathrm{s} \text { sustained } \\
\text { transfer }\end{array}$ \\
\hline Cost in 2008 & $\$ 3600 /$ month & $\$ 1000$ & $\$ 100$ \\
\hline$\$ 1$ buys in 2008 & $2.7 \mathrm{~GB}$ & $128 \mathrm{CPU}$ hours & $10 \mathrm{~GB}$ \\
\hline $\begin{array}{l}\text { Cost/Performance } \\
\text { improvement }\end{array}$ & $2.7 \mathrm{x}$ & $16 \mathrm{x}$ & $10 x$ \\
\hline $\begin{array}{l}\text { Cost to rent } \$ 1 \text { worth } \\
\text { of AWS in } 2008\end{array}$ & $\begin{array}{l}\$ 0.27-\$ 0.40 \\
(\$ 0.10-\$ 0.15 / \mathrm{GB} \times 3 \mathrm{~GB})\end{array}$ & $\begin{array}{l}\$ 2.56 \\
(128 \times 2 \text { VM's@\$0.10 each })\end{array}$ & $\begin{array}{l}\$ 1.20-\$ 1.50 \\
(\$ 0.12-\$ 0.15 / \text { GB-month } \times 10 \mathrm{~GB})\end{array}$ \\
\hline
\end{tabular}

Source: Armbrust, M., A. Fox, R. Griffith, A. D. Joseph, R. Katz, A. Konwinski, mfl, Above the Clouds: A Berkeley View of Cloud Computing'Technical Report No (UCB/EECS-2009-28, UC Berkeley Reliable Adaptive Distributed Systems Laboratory, February, 2009,

Armburst et al. (2009) argue that very large datacentres (tens of thousands of computers) can purchase hardware, network bandwidth, and power for $1 / 5$ to $1 / 7$ the prices offered to a mediumsized (hundreds or thousands of computers) datacentres. Further, they argue, 'the fixed costs of software development and deployment can be amortized over many more machines. Others estimate the price advantage as a factor of 3 to 5 (Rangan, et al., 2008; Bechtolsheim, 2008). Thus, a sufficiently large company could leverage these economies of scale to offer a service well below the costs of a medium-sized company and still make a tidy profit.'

The issue of monopolising or having several major actors control the cloud is not a minor issue. As we are moving from the service economy to the knowledge-based economy, our access, processing and use of information and information technology becomes critical. As we have progressed from an agrarian society to an industrial to a service economy, our dependence on information and ICT has been steadily increasing; and as we move from a service economy to a knowledge-based economy, this dependence has become total.

\section{From Primary to Quaternary}

Society is defined as "an organized group of persons associated together for religious, benevolent, cultural, scientific, political, patriotic, or other purposes" (Online Etymology Dictionary, 2010). As societies evolve, their social structure and their primary means of subsistence change (Elman, 1975; Lenski, 1984). These changes are naturally reflected in the economy of the society and with it the employment pattern.

Fisher (1939, 1952), Clark (1967), Fourastié (1950) and others have argued that an economy can be divided into three sectors ("the three sector hypothesis"): primary (agriculture and extraction of raw material), secondary (manufacturing) and tertiary (services). This division is based on the factors of production, which Wolf (1955) argues, limits the increase in productivity in each sector accordingly. For example the primary sector is dependent on natural growth factors; the secondary sector on mechanical factors and tertiary on relatively unaided human skill, something that is in line with Fourastié arguments.

Fourastié, using the three sector hypothesis, classifies human history into three eras: primary, transitional (or secondary) and tertiary or service era. In his book "The Grand Hope of the 21st 
Century" he states that it is the proportion of people employed in each sector that determines the era in which that society currently finds itself in. He argues that for most of the human history, the majority of the working population have been working with agriculture or extraction of the raw materials (primary: $80 \%$, secondary: 10\% and tertiary: 10\%). Then we had the industrial revolution and the beginning of the transition era (secondary or industrial). Here again he points to a major shift in employment away from the primary sector and towards the secondary sector.

Fourastie foresaw the beginning of the end of the secondary era and beginning of a new transitional period in the 1950s, when industry would begin to show signs of saturation which would result in a shift in the employment pattern away from manufacturing and towards the services.

He also predicted that by the end of the 20th century, we would be in the Tertiary Era, with $85 \%$ of the working population working in the tertiary (service) sector, $10 \%$ working in the secondary (industrial/manufacturing) sector and the remaining 5\% being active in the primary sector. As can be seen from Figure 1, most of the developed countries are approaching the $80 \%$ mark, which is very close to the Fourastié 's predicted threshold.

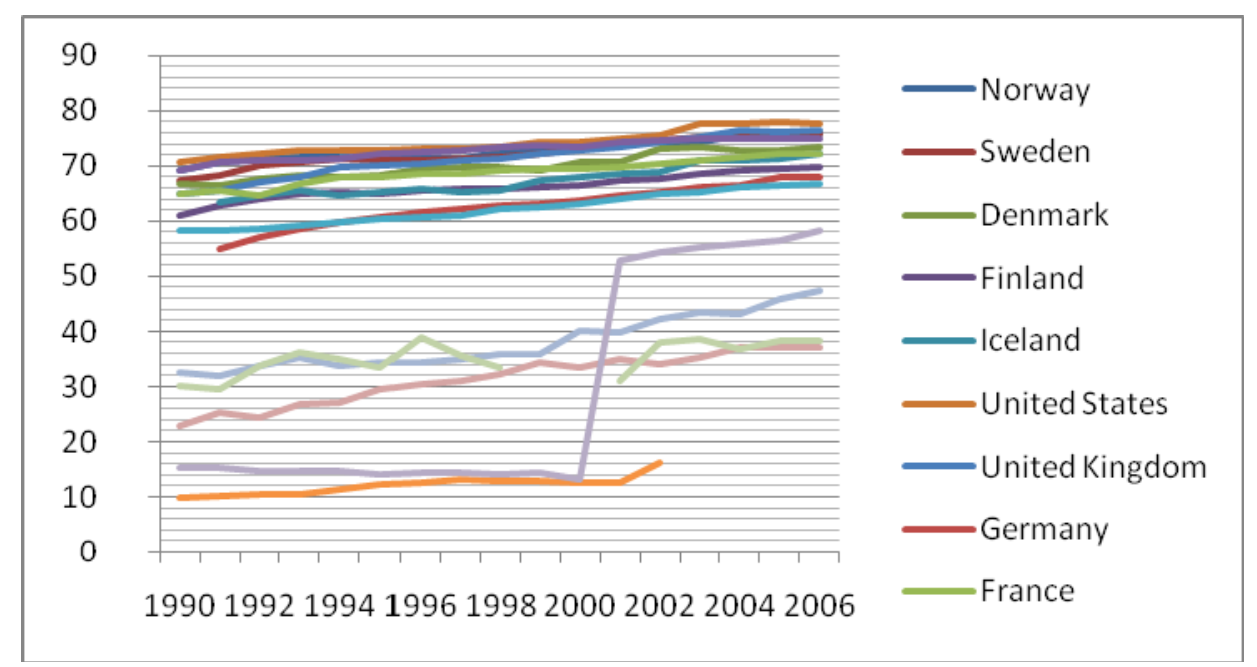

Figure 1: The growing dominance of the service sector in selected countries measured by the total employment share 1990-2007. Source: World Bank

The arrival of the Fourastié's service Era was acknowledged by others (Bell, 1976; Webster, 1995; Bell, 2000), albeit under another title: the "Post-Industrial Society". Fourastié also predicted that in the Tertiary Era the technological progress would not have any impact on the service sector; leading to stagnation in the technological progress. Here again he was referring to the limits that were mentioned earlier, where Primary Era was limited by natural growth, the Secondary or Transition Era was limited by mechanical factor and Tertiary Era will be limited by unaided human skill.

Here, we see that the technological progress in the past 50 years have been so vast that it has effectively removed the limits mentioned by Fourastié. If anything, instead of technical stagnation, we see tremendous advancements; advancements that not only have created new goods and changed the nature (delivery and consumption) of many services, but have also (and most importantly) made knowledge the prime source of power and social dynamism (Bell, 1976). This knowledge is based on access and processing of information. We call the extensive activities such as creating, distributing, using, integrating or manipulating information as belonging to a new sector: the "Quaternary Sector", which is the hall mark of the information era. Table 3 shows the percentage of the working population in each sector and the importance of access to information in each era. 
Table 3. Information requirements and use in different eras

\begin{tabular}{|l|c|c|c|c|}
\cline { 2 - 5 } \multicolumn{1}{c|}{} & Primary sector & Secondary sector & Tertiary sector & Quaternary Sector \\
\hline Traditional Civilization & $70 \%$ & $20 \%$ & $10 \%$ & Low \\
\hline Transitional Period & $20 \%$ & $50 \%$ & $30 \%$ & Medium \\
\hline Tetriary Civilization & $10 \%$ & $20 \%$ & $70 \%$ & High \\
\hline Information-based Civ. & & & & Extremely high \\
\hline
\end{tabular}

\section{The Arrival of the Information Era}

There are many labels and opinions of what defines an information society (Beniger, 1986), but in general we consider a society to be an information society, if a major part of that society is engaged in creating, distributing, using, integrating or manipulating information in one form or the other. In addition this is done through the use of information technologies. The economic counterpart is referred to as the knowledge economy, since the economic activities depend to a large extent on the knowledge gained by accumulating, integrating and processing information.

David and Foray (2003) argue that the 'knowledge-based' economy is a recently coined term that is meant to signify a change from the economies of earlier periods (a sea-change rather than a sharp discontinuity). They argue that this transformation has and is taking place at a number of different levels, these levels being: (1) the acceleration of knowledge production,(2) the rise of intangible capital at macroeconomic level, (3) innovation becoming the dominant activity with its source being ever-more varied and, crucially, (4) the revolution in instruments of knowledge (IT). They also point out that:

"Information technologies can affect knowledge creation in a number of different ways. First there is the ease of access to information. Second, information technologies enhance creative interaction not only among scholars and scientists but, equally among product designers, suppliers and the end customers. Third the new technologies enable the exploration and analysis of the content of gigantic databases, which is in itself a potent means of knowledge enhancement. Finally, all these combine to create large-scale decentralised systems for data gathering, calculation and sharing of the findings."

In the information era or in a knowledge-based economy, access to and processing of information becomes extremely important. The technologies that facilitate the creation, distribution, integration, manipulation and use of information becomes one of the most vital part of the economic infrastructure of the society, without which the society will not be able to function.

Now, if access and usage become so important that the unavailability of either can seriously affect the development and welfare of the society then it falls to the government to step in and either provide the necessary infrastructure or regulate the industry to ensure fair and equitable access for the citizens and businesses alike. After all, this has been the modus-operandi in dealing with all the utilities (water, gas, electricity, telephone and others).

\section{Information Infrastructure and Services as Public Goods}

In economics a commodity is said to be a private good when its consumption or use is both rivalrous and excludable (Dasgupta, 2007). Rivalrous means that the consumption of one unit of the good by a consumer will reduce the total amount available to the other consumers by one unit; and excludable means that the right to that good is protected by some kind of law. Most of the goods, such as food, clothing, medicine, etc, that we consume are in this sense private goods. In 
contrast, public goods are non-rivalrous (e.g. elementary/secondary education, public security, national defence, lighthouse, water supply, electricity, roads) and non-excludable (available to all).

There are some problems with providing the public with non-rivalrous goods and services since charging a price for production and distribution of the good or the service will restrict access while at the same time exclude those who cannot pay even the minimum set prices. A good example of this is public security or national defence. How can a private company charge a citizen or a foreign national visiting the country for local policing or national defence?

In these situations, it is often difficult or even undesirable to finance production/distribution by charging a specific price. Hence, private companies have been historically reluctant (lack of incentive) to enter these markets without some kind of government subsidy, financial guarantees, being granted a monopoly status or all of the above.

It therefore often falls on the government to carry the burden and provide the public goods and services. Government is also the only authority that has both the authority and coercive power to determine the price of these goods and services and collect them through taxation.

However, this does not mean that private firms are totally absent in these public goods/services markets. In some countries such as US or UK with market economies, many public goods such as water, gas, or electricity are provided by private companies. These companies both private and public are called the public utility companies. Opinions of course differ.

"Opinions differ as to the characteristics that an industry must possess to merit classification as a public utility, since all industries in a sense serve the public. By its nature a public utility is often a monopoly and as such is not prevented by competing companies from charging exorbitant prices. It usually operates under a license or franchise by which it enjoys special privileges, such as the right of eminent domain. Finally, it may supply an essential service, such as water or light, the unavailability of which would injuriously affect public health and welfare" (" Public utility," 2008).

Public utilities often use civic infrastructure to produce or deliver goods and services. Civic infrastructures are those basic facilities, services and installations needed for the proper functioning of a developing or developed community or society. They may include communication systems (road, bridges, telephone system, etc.), transportation, water, gas, electricity, and public institutions including schools, post offices, etc. Civic infrastructure is the core foundation of any society, unavailability of which can seriously affect the development and welfare of that society.

In a knowledge-based economy, the information infrastructure is part of the civic infrastructure, since without it the society will simply not function as it should. However, here we see how major corporations are already trying hard to establish semi-monopolies/oligopolies to control access to the internet. The term Net Neutrality has become an early warning phrase for those who are concerned with the future of cloud computing.

"Though the term did not enter popular use until several years later, since the early 2000 s advocates of net neutrality and associated rules have raised concerns about the ability of broadband providers to use their last mile infrastructure to block Internet applications and content (e.g., websites, services, protocols), particularly those of competitors. In the US particularly, but elsewhere as well, the possibility of regulations designed to mandate the neutrality of the Internet has been subject to fierce debate.

Neutrality proponents claim that telecom companies seek to impose a tiered service model in order to control the pipeline and thereby remove competition, create artificial scarcity, and oblige subscribers to buy their otherwise uncompetitive services. Many be- 
lieve net neutrality to be primarily important as a preservation of current freedoms (Lessing \& McChesney, 2006)." ("Network Neutrality," 2010)

\section{Conclusion}

One must remember that in the information era, "Knowledge-based activities emerge when people, supported by information and communication technologies, interact in concerted efforts to co-produce (i.e. create and exchange) new knowledge. Typically, this involves three main elements: a significant number of a community's members combine to produce and reproduce new knowledge (diffuse sources of innovation); the community creates a "public" space for exchanging and circulating the knowledge (Dasgupta \& David, 2002); new information and communication technologies are intensively used to codify and transmit the new knowledge." (David \& Foray, 2003)

This is only possible if the necessary infrastructure is in place and access is available to all. From what we see today large actors are positioning themselves to control not only the basic Internet access through abolishment of the network neutrality, but also by creating private mega datacentres with a metering payment model.

Throughout the history, we have witnessed the creation of natural monopolies, oligopolies or "dominant few" in various industries, which eventually led to governments regulating those industries. It happened in all industries that we call utilities, such as gas, electricity, water and telecommunications. It will eventually happen in Internet infrastructure and cloud computing as well. The issue here is when. We can already see the beginning of this in various countries. For example, Australians have begun to question the lack of oversight of the cloud computing.

"Compared with other utility or critical industries, it is reasonable to say that information technology is only lightly regulated. If you step beyond technology manufacturing, of which there is little in Australia, and telecommunication service providers being monitored by the Australian Media and Communication Authority (ACMA), this is especially so.

Instead, most ICT companies - including the new breed of cloud computing providers - are left under the broad watch of the Australian Securities and Investment Commission (ASIC) and the Australian Competition and Consumer Commission (ACCC). A simple search of the current policies of ASIC, ACCC and ACMA reveals that beyond email scams and spam, none of these organisations is paying sufficient attention to the new industrial phenomenon that cloud computing represents.

Indeed, even the reported government policy thinking to date appears limited to how to exploit cloud computing for the sake of internal efficiency or security, rather than about what the reality of paying an offshore firm not required to be registered for Goods and Service Tax (GST) means for Australia' s taxation revenue. If one was to assume for a moment that cloud computing, in all its "as-a-service" forms, will become the dominant model for provision of ICT, then like any core element of economic prosperity, be it water, power, health, travel or of course money, this increasingly attractive market requires oversight." (Higgins, 2010)

The need for oversight was also mentioned by none other than Brad Smith, senior vice president and general counsel of Microsoft Corporation. On 20 January 2010, Brookings Institute hosted a discussion session, in which Mr. Smith was the keynote speaker. In his speech he urged Congress to consider new legislation to regulate the cloud. He stated:

"We need Congress to modernize the laws, adapt them to the cloud, and adopt new measures to protect privacy and promote security. That's why we've concluded that we 
need a cloud computing advancement act that will promote innovation, protect consumers, and provide the executive branch with the new tools needed for a new technology era."(Smith, 2010, p.18)

The call for regulations was also echoed by Kristin Lovejoy of the IBM. She is IBM's director of Governance and Risk Management Strategy. According to Condon (2009), Lovejoy told the federal regulators that the industry would benefit from regulations.

"The cloud computing sector would benefit, Lovejoy said, from standards similar to the PCI Security Standards, which were formed by major credit card companies to regulate payment account data security.

"We could define for the commercial sector a set of simplistic foundational controls, give them the ability to understand what they must do, and then build on top of that," she said.

In the industry's current state, "we don't know what we need to do, we don't know what we need to protect," Lovejoy said. "The technologies are there but not able to fully help us."'(Condon, 2009)

Now there are those (Priest, 1993) who may disagree with the principle of direct or indirect government interference in the market place. However, we cannot ignore the history and the negative influence of dominant corporations on the societies within which they have operated (Demsetz, 1968; Hirsh, 2002). The negative effects can include, among other things, higher prices, lower levels of output, lower quality levels and a slower advance in the development and application of new technology («What is a monopoly? by The Linux Information Project (LINFO)», 2005).

Today we are in a transition period from a tertiary civilization into the information era leaving a regulatory vacuum that the governments (at the national level) and international bodies (at the global level) have to fill. We have to address such issues as data privacy, net neutrality, standards, quality of service guarantees, prohibition of information embargo as a political tool, national and international antitrust laws, and many other issues that has not yet been addressed properly. Each and every issue present us with a particular challenge and opportunity for research, which hopefully will be addressed in a speedy fashion.

\section{References}

Armbrust, M., Fox, A., Griffith, R., Joseph, A. D., Katz, R. H., Konwinski, A., Lee, G., et al. (2009). Above the clouds: A Berkeley view of cloud computing. EECS Department, University of California, Berkeley, Tech. Rep. UCB/EECS-2009-28.

Bechtolsheim, A. (2008, December). Cloud computing and cloud networking. Talk at UC Berkeley.

Bell, D. (1976). The coming of post-industrial society: A venture in social forecasting. Basic books.

Bell, D. (2000). The coming of post-industrial society. The Urban Lawyer, 6, 738.

Beniger, J. R. (1986). The control revolution: Technological and economic origins of the information society. Harvard University Press.

Berg, S. V., \& Tschirhart, J. (1989). Natural monopoly regulation. Cambridge Books.

Buyya, R., Yeo, C. S., Venugopal, S., Broberg, J., \& Brandic, I. (2009). Cloud computing and emerging IT platforms: Vision, hype, and reality for delivering computing as the 5th utility. Future Generation Computer Systems, 25(6), 599-616.

Clark, C. (1967). The conditions of economic progress. London: Macmillan.

Condon, S. (2009, March 18). US regulator questions cloud computing security. ZDNet.com. Retrieved from http://www.zdnetasia.com/us-regulator-questions-cloud-computing-security-62052292.htm 
Dasgupta, P. (2007). Economics: A very short introduction. USA: Oxford University Press.

Dasgupta, P., \& David, P. A. (2002). Toward a new economics of science. In P. Mirowski \& E. Sent (Eds.), Science bought and sold: Essays in the Economics of Science (pp. 219-244). London: The University of Chicago Press.

David, P. A., \& Foray, D. (2003). Economic fundamentals of the knowledge society. Policy Futures in Education, 1(1), 20-49.

Demsetz, H. (1968). Why regulate utilities. Journal of Law and Economics, 11(1), 55-65.

Elman, S. R. (1975). Origins of the state and civilization: The process of cultural evolution. W. W. Norton \& Company.

Fisher, A. G. B. (1939). Production, primary, secondary and tertiary. Economic Record, 15(1), 24-38.

Fisher, A. G. B. (1952). A note on tertiary production. The Economic Journal, 820-834.

Fourastié, J. (1950). Le grand espoir du XXe siècle: progrès technique, progrès économique, progrès social. Presses universitaires de France.

Griffin, J., Oates, J., Farr, S., \& Robertson, S. (2010, March 30). Cloud computing: Keeping control of your data and a handle on costs in a cloud world $\mid$ Accountancy Age \& Financial Director web seminars. Accountancy Age \& Financial Director web seminars. Retrieved November 24, 2010, from http://finance.brighttalk.com/node/736

Hamilton, J. (2008). Internet-scale service efficiency. Large-Scale Distributed Systems and Middleware (LADIS) Workshop (September 2008).

Higgins, S. (2010, November 16). Australia needs a cloud computing regulator. Delimiter. Retrieved November 23, 2010, from http://delimiter.com.au/2010/11/16/australia-needs-a-cloud-computingregulator/

Hirsh, R. F. (2002). Power loss: The origins of deregulation and restructuring in the American electric utility system. The MIT Press

Laudon, K., \& Laudon, J. (2009). Management information systems: Global edition (11th ed.). Pearson Education.

Lenski, G. E. (1984). Power and privilege: A theory of social stratification. The University of North Carolina Press.

Lessing, L., \& McChesney, R. W. (2006, June 8). No tolls on the internet. Retrieved November 15, 2010, from http://www.washingtonpost.com/wp-dyn/content/article/2006/06/07/AR2006060702108.html

Network Neutrality. (2010). Wikipedia. Retrieved from http://en.wikipedia.org/wiki/Network neutrality

Notebaert, R. C. (1995). Technology's contribution to the competitive marketplace [telecommunication industry]. IEEE Communications Magazine, 33(12), 52-54. doi:10.1109/35.476921

Panasonic ushers in the cloud computing era with IBM LotusLive. (2010, January 15). . Retrieved April 3, 2011, from http://news.taume.com/Technology/Tech-Deals/panasonic-ushers-in-the-cloud-computingera-with-ibm-lotuslive-14751\#146;s\%20suite $\% 20 \mathrm{of} \% 20$ collaboration $\% 20$ services

Priest, G. L. (1993). Origins of utility regulation and the theories of regulation debate. The Journal of Law and Economics., 36, 289.

Public utility facts, information, pictures | Encyclopedia.com articles about public utility. (2008). The Columbia Encyclopedia, 6th ed. Retrieved April 12, 2010, from http://www.encyclopedia.com/topic/public_utility.aspx\#2-1E1:utilpub-full

Rangan, K., Cooke, A., Post, J., \& Schindler, N. (2008). The cloud wars: 100+ billion at stake. The Analyst, (May), 1-90. 
Rivals Set Their Sights on Microsoft Office: Can They Topple the Giant? (2007, August 22). Knowledge@Wharton. Retrieved November 1, 2010, from http://knowledge. wharton.upenn.edu/article.cfm?articleid=1795

Rosenberg, J., \& Mateos, A. (2010). The cloud at your service. Greenwich, CT, USA: Manning Publication.

Smith, B. (2010, January 20). Cloud computing for business and society. Retrieved from http://www.microsoft.com/presspass/presskits/cloudpolicy/docs/20100120 transcript.pdf

Society (n.d.). Online Etymology Dictionary. Retrieved 2010, April 21 from http://dictionary.reference.com/browse/society

Vouk, M. A. (2004). Cloud computing-Issues, research and implementations. Journal of Computing and Information technology, 16(4), 235-246.

Webster, F. (1995). Theories of the information society. Psychology Press.

Weinhardt, C., Anandasivam, A., Blau, B., Borissov, N., Meinl, T., Michalk, W., \& Stoesser, J. (2011). Cloud computing-A classification, business models and research directions. Business \& Information Systems Engineering, 1(5), 6.

What is a monopoly? by The Linux Information Project (LINFO). (2005, January 20). . Retrieved October 2, 2010, from http://www.linfo.org/monopoly.html

Wolfe, M. (1955). The concept of economic sectors. The Quarterly Journal of Economics, 69(3), 402.

Wyld, D. C. (2009). The utility of cloud computing as a new pricing - and consumption - model for information technology. International Journal of Database Management Systems, 1(1), 1-20.

\section{Biographies}

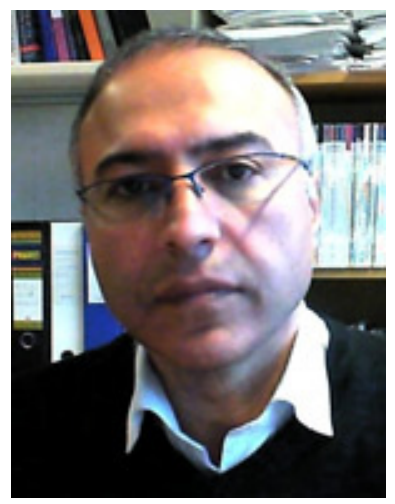

Abbas Strommen-Bakhtiar is an associate professor at the Centre for Enterprise Architecture and Information Systems, Graduate School of Business, University of Nordland. He has BScs in Aerospace Engineering Technology and Computer Science, MScs in Information Technology and Computer Integrated Manufacturing and a $\mathrm{PhD}$ in Strategic management. His main interests are in the areas of Management Information Systems and Strategic Management. He is currently working on several projects such as open source educational framework for Virtual University, the application and use of decision support systems for managing operations in extreme environments.

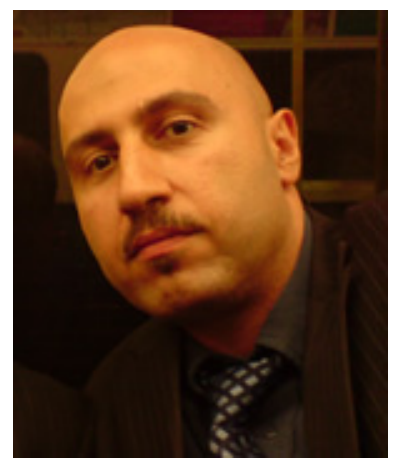

Amir reza Razavi is a research associate at the University of Surrey, where he leads the Virtual University project. He has a BSc in Software Engineering (Shiraz Azad University 1996-Iran), two MScs (Iran University of Science and Technology 1999-Iran \& University of Surrey 2003-UK) and a $\mathrm{PhD}$ on computer science (University of Surrey 2009-UK). His main interest has been distributed computing, longrunning transactions in non-conventional environments and interaction models for educational systems. He has contributed in several EU projects (OPAALS, DBE and ASPIC) and currently designs an open source educational framework for Virtual University project. 